\title{
The Contribution of Whole Blood Viscosity to the Process of Aortic Valve Sclerosis
}

\author{
Alper Sercelik Abbas Fikret Besnili \\ Department of Cardiology, School of Medicine, Sanko University, Gaziantep, Turkey
}

\section{Significance of the Study}

- The objective of this study was to assess whole blood viscosity (WBV), a marker of shear stress, as a major risk factor contributing to aortic valve sclerosis (AVS). This study demonstrated that WBV was independently associated with AVS. As an easily measurable laboratory variable, WBV could be a useful indicator of AVS.

\section{Keywords}

Aortic valve sclerosis - Whole blood viscosity - Shear stress .

Receiver-operating characteristic curve

\section{Abstract}

Objective: We aimed to investigate whether increased whole blood viscosity (WBV) could be an important factor for the occurrence of aortic valve sclerosis (AVS). Subjects and Methods: A total of 209 patients were enrolled in the study. WBV was calculated using the hematocrit and total plasma protein at a low shear rate (LSR) and a high shear rate (HSR). AVS was defined as irregular valve thickening and calcification (without evidence of outflow obstruction) documented by a peak transvalvular velocity $<2.5 \mathrm{~m} / \mathrm{s}$ on echocardiographic examination. The patient group consisted of 109 patients with AVS (77 females, 32 males), and 100 subjects without AVS (65 females, 35 males) were assigned to the control group. Results: In the AVS group, WBV values were significantly higher for HSR (17.4 \pm 0.5 vs. $17.1 \pm 0.7208 \mathrm{~s}^{-1}$, $p<0.001)$ and LSR $\left(65.9 \pm 12.5\right.$ vs. $59.7 \pm 16.70 .5 \mathrm{~s}^{-1}, p=$ 0.002 ). In multivariate logistic regression analysis, WBV at

\section{KARGER}

E-Mail karger@karger.com www.karger.com/mpp (c) 2018 The Author(s)

Published by S. Karger AG, Basel

Karger

Open access

This is an Open Access article licensed under the Creative Commons Attribution-NonCommercial-4.0 International License (CC BY-NC) (http://www.karger.com/Services/OpenAccessLicense), applicable to the online version of the article only. Usage and distribution for commercial purposes requires written permission.
HSR and LSR were independent predictors of AVS (odds ratio, OR: $2.24,95 \%$ confidence interval, $\mathrm{Cl}$ : 1.38-3.64, $p=0.001$; OR: $1.026,95 \% \mathrm{Cl}: 1.006-1.046, p=0.01$, respectively). Receiver-operating characteristic (ROC) curve analysis indicated that a WBV cutoff value of 65.4 at LSR had a sensitivity of $46.8 \%$ and a specificity of $60.0 \%$ (area under the ROC curve, AUC: $0.615,95 \% \mathrm{Cl}: 0.535-0.696, p=0.004)$, and a WBV cutoff value of 17.1 at HSR had a sensitivity of $61.5 \%$ and specificity of $53 \%$ (AUC: $0.648,95 \% \mathrm{Cl}: 0.571-0.725, p<0.001$ ) for the prediction of AVS. Conclusion: This study demonstrated that WBV was independently associated with AVS. WBV could be an indicator of inflammation and vessel remodeling without evidence of outflow obstruction. @ 2018 The Author(s) Published by S. Karger AG, Basel

\section{Introduction}

Aortic valve sclerosis (AVS) is a frequent finding at echocardiography in the elderly population [1]. AVS is also an incremental risk factor related to the enhanced deaths ratio from cardiovascular events [1]. The mor- 
phology of atherosclerosis and AVS are similar and associated with similar risk factors [2]. Additionally, it has been claimed that mechanical forces such as blood pressure, membrane tension, and fluid shear stress contribute to the calcification of the aortic valve (AV) [3]. Lesions frequently occur at the aortic side of the leaflets, an area of high turbulent flow and tensile stress with oscillatory shear stress [4]. The center of the valve cusp has the greatest mechanical stress and is more frequently involved than the commissures.

Whole blood viscosity (WBV), a marker of shear stress, may be considered as a major cardiovascular risk factor contributing to AVS. Measurement of WBV may be challenging due to nonstandardized methods in the laboratory, lack of advanced instruments, and insufficient research data [5]. High WBV could disrupt endothelial integrity at the foci of enhanced mechanical stress, such as the aortic surface of AV leaflets in the coronary sinus area of the aorta. Therefore, we aimed to investigate whether increased WBV could be an important factor for the occurrence of AVS in addition to traditional cardiovascular risk factors.

\section{Subjects and Methods}

\section{Patient Population}

This is a cross-sectional clinical study in which 209 patients were enrolled from August 2014 to November 2016. The patients were divided into 2 groups based on the presence or absence of AVS on echocardiographic examination. The patient group consisted of 109 patients with AVS (77 females, 32 males); 100 subjects without AVS ( 65 females, 35 males) comprised the control group. AVS was defined as irregular valve thickening and calcification, without evidence of outflow obstruction, as documented by a peak transvalvular velocity $<2.5 \mathrm{~m} / \mathrm{s}$ based on a previous study [6].

Medical history was obtained from patients and their hospital records, and physical examination was performed on all patients and controls. Demographic, clinical, and laboratory data of the subjects were collected from medical records. Exclusion criteria were prior coronary artery bypass surgery or percutaneous coronary intervention, left ventricular ejection fraction $<50 \%$, a history of heart valve surgery, bicuspid AV, rheumatic heart disease, renal failure, acute or chronic liver disease, chronic pulmonary disease, acute and chronic infections or inflammatory diseases, malignancies, hematological disorders (including anemia), or oral warfarin therapy. Anemia was defined as a reduction in either the percentage of red blood cells (hematocrit, Hct) or a reduction in the concentration of hemoglobin in a sample of venous blood compared with reference values.

Hypertension was defined as a systolic blood pressure of 140 $\mathrm{mm} \mathrm{Hg}$ or more or a diastolic blood pressure of $90 \mathrm{~mm} \mathrm{Hg}$ or more, or taking antihypertensive medication. Diabetes mellitus was defined as the use of antidiabetic drugs and a fasting blood glucose $>126 \mathrm{mg} / \mathrm{dL}$. Hyperlipidemia was identified in patients with total cholesterol $>200 \mathrm{mg} / \mathrm{dL}$, low-density lipoprotein (LDL) $>130 \mathrm{mg} / \mathrm{dL}$, triglyceride levels $>150 \mathrm{mg} / \mathrm{dL}$, and in patients treat- ed with lipid-lowering drugs. Body mass index was defined as weight in kilograms divided by the square of the height in meters. The study was approved by the Institutional Ethics Committee, and written informed consent was obtained from all the patients.

\section{Transthoracic Echocardiography}

Each patient underwent a complete transthoracic echocardiography using the recommendations from the American Society of Echocardiography's Guidelines and Standards Committee [7]. Echocardiograms were performed using a Vivid S5 (General Electronic, Waukesha, WI, USA) with a 2.5- to 3.5-MHz transducer, placed on the IIIrd-IVth left intercostal space along the parasternal line, with patients being supine in left lateral decubitus position with the head of the bed kept at $30^{\circ}$. All examinations were performed by an experienced cardiologist blinded to the patient's clinical information.

AVS was defined as the presence of irregularly increased echogenicity and thickening of the leaflets, no restriction of leaflet motion, with peak instantaneous transaortic jet velocity $<2.5 \mathrm{~m} / \mathrm{s}$. Patients with poor echogenicity were excluded from the study. AVS was defined as restricted systolic opening of the valve leaflets; patients with a mean transvalvular pressure gradient of at least 10 $\mathrm{mm} \mathrm{Hg}$ and/or with peak instantaneous transaortic jet velocity $>2.5 \mathrm{~m} / \mathrm{s}$ were also excluded from the study. Mitral annular calcification (MAC) was defined echocardiographically as an echodense, irregular shelf-like structure involving the mitral valve annulus with associated acoustic shadowing.

\section{Laboratory Analysis}

Blood samples were drawn through venipuncture from all subjects following $12 \mathrm{~h}$ of fasting into standardized tubes containing dipotassium ethylenediaminetetraacetic acid (EDTA). All hematological measurements were performed using the XT-2000i analyzer (Sysmex Corporation of America, Long Grove, IL, USA). Biochemical measurements were made using a molecular analyzer (Roche Diagnostics, Manheim, Germany).

\section{Extrapolation of $W B V$}

The calculation of WBV was done with a formula from Hct and total plasma protein (TP) for wall shear stress [8]. WBV was calculated for both LSR $\left(0.5 \mathrm{~s}^{-1}\right)$ and HSR $\left(208 \mathrm{~s}^{-1}\right)$ from Hct and TP protein concentration using a validated formula [8].

HSR: WBV $\left(208 \mathrm{~s}^{-1}\right)=(0.12 \times \mathrm{Hct})+0.17(\mathrm{TP}-2.07)$.

LSR: WBV $\left(0.5 \mathrm{~s}^{-1}\right)=(1.89 \times \mathrm{Hct})+3.76(\mathrm{TP}-78.42)$.

\section{Statistical Analysis}

The Statistical Package for Social Sciences (SPSS Inc., Chicago, IL, USA) for Windows was used for all statistical calculations. Categorical variables were expressed as numbers and proportions while continuous variables were expressed as means \pm SD. The ShapiroWilk test was used to evaluate whether the distribution of continuous variables was normal. Continuous variables were compared with the Student $t$ test (while comparing normally distributed variables) or Mann-Whitney U test (while comparing nonnormally distributed variables). The $\chi^{2}$ test was used to compare groups regarding categorical variables. Variables with $p<0.10$ in univariate analysis were identified as potential risk markers and included in the full multivariate logistic regression model as covariates. The receiver-operating characteristic (ROC) curve was used to demonstrate the sensitivity and specificity of WBV at HSR and LSR and their cutoff values for predicting AVS. A value of $p<0.05$ was considered as significant. 
Table 1. Baseline characteristics and laboratory findings of the patients with aortic value sclerosis (AVS) and controls

\begin{tabular}{|c|c|c|c|}
\hline Parameters & Controls $(n=100)$ & $\operatorname{AVS}(n=109)$ & $p$ values \\
\hline Age, years & $66.0 \pm 6.4$ & $65.0 \pm 7.4$ & 0.296 \\
\hline \multicolumn{4}{|l|}{ Gender } \\
\hline Females & 65 & 77 & 0.458 \\
\hline Males & 35 & 32 & \\
\hline Body mass index & $30.3 \pm 3.8$ & $31.2 \pm 5.0$ & 0.168 \\
\hline Hyperlipidemia & $51(51.0 \%)$ & $65(59.6 \%)$ & 0.214 \\
\hline Diabetes mellitus & $34(34 \%)$ & $45(41.3 \%)$ & 0.318 \\
\hline Hypertension & $51(51.0 \%)$ & $63(57.8 \%)$ & 0.334 \\
\hline Smoking & $30(30 \%)$ & $24(22 \%)$ & 0.208 \\
\hline Systolic blood pressure, $\mathrm{mm} \mathrm{Hg}$ & $124.53 \pm 19.4$ & $127.94 \pm 18.4$ & 0.194 \\
\hline Diastolic blood pressure, $\mathrm{mm} \mathrm{Hg}$ & $74.7 \pm 15.9$ & $74.3 \pm 10.3$ & 0.829 \\
\hline Heart rate, bpm & $68.6 \pm 12.7$ & $67 \pm 11.7$ & 0.332 \\
\hline \multicolumn{4}{|l|}{ Echocardiographic measurements } \\
\hline Ejection fraction, $\%$ & $60.8 \pm 3.2$ & $59.8 \pm 5.0$ & 0.121 \\
\hline Left atrial diameter, $\mathrm{cm}$ & $3.75 \pm 0.3$ & $3.78 \pm 0.4$ & 0.661 \\
\hline Ascending aorta diameter, $\mathrm{cm}$ & $3.49 \pm 0.30$ & $3.49 \pm 0.26$ & 0.998 \\
\hline Aortic valve jet velocity, m/s & $1.33 \pm 0.18$ & $1.97 \pm 0.13$ & $<0.001$ \\
\hline Mitral annular calcification & $14(14 \%)$ & $28(25.7 \%)$ & 0.039 \\
\hline \multicolumn{4}{|l|}{ Medications } \\
\hline$\beta$-Blockers & $35(35.0 \%)$ & $35(32.4 \%)$ & 0.769 \\
\hline ACE inhibitors/ARB & $41(41.0 \%)$ & $48(44.0 \%)$ & 0.677 \\
\hline ASA & $37(37.0 \%)$ & $42(38.5 \%)$ & 0.887 \\
\hline Statins & $26(26.0 \%)$ & $25(22.9 \%)$ & 0.632 \\
\hline \multicolumn{4}{|l|}{ Laboratory parameters } \\
\hline $\mathrm{WBC}, \times 10^{3} / \mu \mathrm{L}$ & $7.7 \pm 2.3$ & $7.3 \pm 1.9$ & 0.173 \\
\hline Hemoglobin, g/dL & $13.7 \pm 1.2$ & $13.8 \pm 1.0$ & 0.465 \\
\hline Hct, $\%$ & $40.9 \pm 5.4$ & $41.6 \pm 4.6$ & 0.266 \\
\hline Platelets, $\times 10^{3} / \mu \mathrm{L}$ & $256.8 \pm 73.0$ & $244.0 \pm 57.7$ & 0.159 \\
\hline Glucose, mg/dL & $115.8 \pm 41.4$ & $119.0 \pm 49.1$ & 0.612 \\
\hline Creatinine, $\mathrm{mg} / \mathrm{dL}$ & $1.0 \pm 0.2$ & $0.9 \pm 0.2$ & 0.112 \\
\hline hs-CRP, mg/dL & $2.5 \pm 2.4$ & $3.4 \pm 3.3$ & 0.044 \\
\hline Total cholesterol, mg/dL & $195.2 \pm 41.3$ & $205.8 \pm 44.5$ & 0.079 \\
\hline LDL cholesterol, mg/dL & $119.0 \pm 36.3$ & $127.9 \pm 38.0$ & 0.084 \\
\hline HDL cholesterol, mg/dL & $45.3 \pm 10.2$ & $47.3 \pm 10.1$ & 0.162 \\
\hline Triglycerides, mg/dL & $154.8 \pm 68.6$ & $152.7 \pm 74.6$ & 0.833 \\
\hline Albumin, mg/dL & $4.2 \pm 0.8$ & $4.4 \pm 0.8$ & 0.424 \\
\hline Total protein, g/L & $73.8 \pm 6.3$ & $75.0 \pm 4.9$ & 0.104 \\
\hline WBV at HSR, $208 \mathrm{~s}^{-1}$ & $17.1 \pm 0.7$ & $17.4 \pm 0.5$ & $<0.001$ \\
\hline WBV at LSR, $0.5 \mathrm{~s}^{-1}$ & $59.7 \pm 16.7$ & $65.9 \pm 12.5$ & 0.002 \\
\hline
\end{tabular}

ACE, angiotensin-converting enzyme; ARB, angiotensin receptor blocker; ASA, acetylsalicylic acid; Hct, hematocrit, HDL, high-density lipoprotein; hs-CRP, high-sensitivity C-reactive protein; HSR, high shear rate; LDL, low-density lipoprotein; LSR, low shear rate; WBC, white blood cell count; WBV, whole blood viscosity.

\section{Results}

The mean age of the participants was $65.5 \pm 6.9$ years. The baseline characteristics, laboratory values, and echocardiographic measurements of both study groups are presented in Table 1. There were no significant differences between the groups with respect to mean age, gender, body mass index, diabetes mellitus, hypertension, hyperlipidemia, and smoking. In echocardiographic measurements, mean AV jet velocity was $1.97 \pm 0.13 \mathrm{~m} / \mathrm{s}$ in the patient group and $1,33 \pm 0.18 \mathrm{~m} / \mathrm{s}$ in the control group $(p<0.001)$. Mean left ventricular ejection fraction, left atrial size, and ascending aorta diameter were similar in both groups. The presence of MAC was significantly higher in the AVS group than in the control group (28 [25.7\%] vs. $14[14 \%] ; p=0.039)$. 
Table 2. Model 1: independent predictors of aortic valve sclerosis

\begin{tabular}{lllll}
\hline Parameters & OR & \multicolumn{2}{l}{$95 \% \mathrm{CI}$ for OR } & \multirow{2}{*}{$\begin{array}{l}p \\
\text { values }\end{array}$} \\
\cline { 3 - 4 } & & lower & upper & \\
\hline MAC & 2.015 & 0.961 & 4.227 & 0.064 \\
hs-CRP & 1.087 & 0.982 & 1.205 & 0.109 \\
LDL cholesterol & 1.008 & 1.000 & 1.016 & 0.063 \\
WBV at HSR, 208 s & 2.245 & 1.381 & 3.648 & 0.001 \\
\hline
\end{tabular}

$\mathrm{CI}$, confidence interval; hs-CRP, high-sensitivity C-reactive protein; HSR, high shear rate; LDL, low-density lipoprotein; MAC, mitral annular calcification; OR, odds ratio; WBV, whole blood viscosity.

Table 3. Model 2: independent predictors of aortic valve sclerosis

\begin{tabular}{lllll}
\hline Parameters & OR & \multicolumn{2}{l}{$95 \%$ CI for OR } & \multirow{2}{*}{ p values } \\
\cline { 3 - 4 } & & lower & upper & \\
\hline MAC & 2.073 & 0.995 & 4.319 & 0.052 \\
hs-CRP & 1.088 & 0.983 & 1.205 & 0.103 \\
LDL cholesterol & 1.007 & 0.999 & 1.015 & 0.078 \\
WBV at LSR, 0.5 s & 1.026 & 1.006 & 1.046 & 0.010 \\
\hline
\end{tabular}

LSR, low shear rate (see also Table 2 for abbreviations).

Both groups were similar in regard to laboratory parameters except for higher high-sensitivity C-reactive protein levels $(p=0.044)$ in the AVS group. Total and LDL cholesterol levels were higher in the AVS group, but the differences were not statistically significant ( $p$ values: 0.079 and 0.084 , respectively). In the AVS group, WBV values were significantly higher for HSR than in the control group (17.4 $\left.\pm 0.5 \mathrm{vs} .17 .1 \pm 0.7208 \mathrm{~s}^{-1}, p<0.001\right)$ and LSR $\left(65.9 \pm 12.5\right.$ vs. $\left.59.7 \pm 16.70 .5 \mathrm{~s}^{-1}, p=0.002\right)$.

In order to find predictors of AVS, 2 multivariate logistic regression models were considered separately by WBV at HSR and LSR values, which contain MAC, high-sensitivity C-reactive protein, and LDL cholesterol (Tables 2, 3). The WBV values at HSR and LSR were independent predictors of AVS (WBV at HSR: odds ratio, OR: $2.24,95 \%$ confidence interval, CI: $1.38-3.64, p=$ 0.001; WBV at LSR: OR: 1.026, 95\% CI: $1.006-1.046, p=$ 0.01 ; Tables 2,3$)$. In the ROC curve analysis, a WBV cutoff value of 65.4 at LSR had a sensitivity of $46.8 \%$ and a specificity of $60.0 \%$ for the prediction of AVS (area under the ROC curve, AUC: $0.615,95 \%$ CI: 0.535-0.696, $p=$ 0.004 ), and a WBV cutoff value of 17.1 at HSR had a sen-

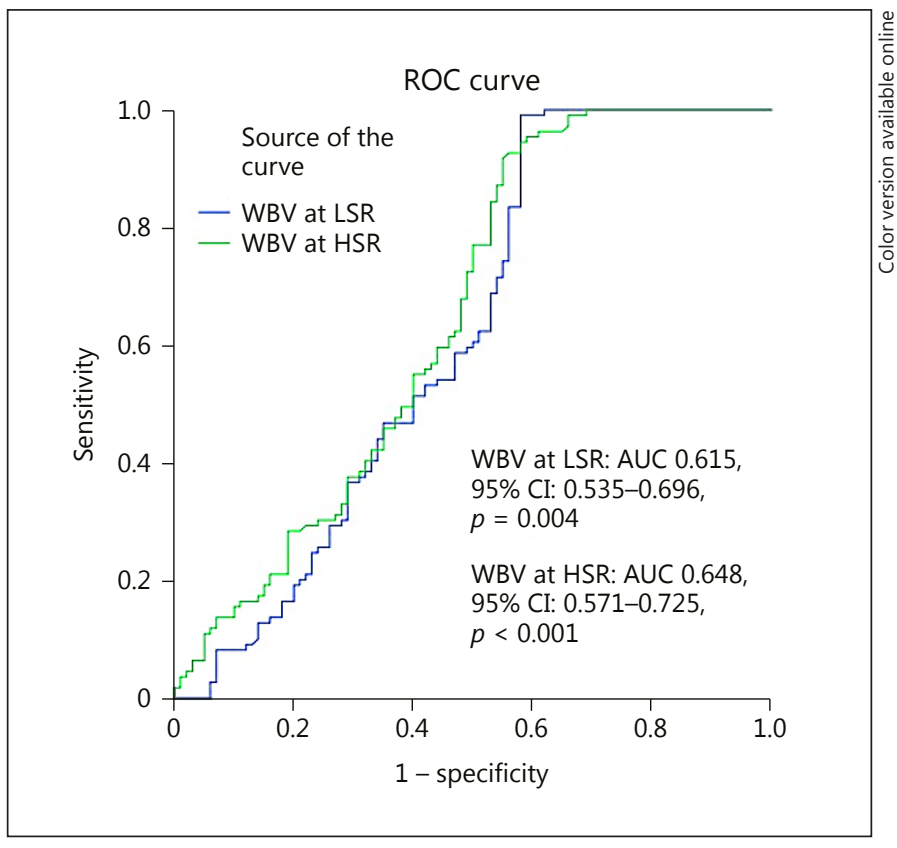

Fig. 1. Comparison of receiver-operating characteristic (ROC) curves for whole blood viscosity (WBV) at low (LSR) and high shear rate (HSR). 95\% confidence intervals (CIs) for ROC are also displayed. AUC, area under the ROC curve. sitivity of $61.5 \%$ and specificity of $53 \%$ for the prediction of AVS (AUC: $0.648,95 \%$ CI: $0.571-0.725, p<0.001$; Fig. 1).

\section{Discussion}

The present study demonstrated that WBV values were higher in the AVS group than in the controls. Furthermore, WBV values at HSR and LSR were independently associated with AVS. WBV is a measure of the resistance of blood to flow and contributes to endothelial shear stress [9]. This biophysical property makes it a critical determinant of friction against the vessel walls. Shear stress modulates the orientation of endothelial cells in the direction of flow and the "waviness" of the luminal surface of the vessel [10]. Balachandran et al. [11] reported that the exposure of pulsatile shear stress on the aortic surface causes an increase in inflammatory mediator cells. Turbulent flow and resulting oscillatory shear stress on the aortic surface of AV leaflets and in the coronary sinus area lead to increased permeability of endothelial 
cells and proatherogenic phenotypic transformation, including augmented matrix calcification [12]. As a common pathomechanism of AVS and atherosclerosis, sclerosis and subsequent calcification of AV leaflets is promoted by the same traditional risk factors that lead to endothelial dysfunction, as well as hemodynamic factors involving formation of secondary flow, where the vessel wall is exposed to oscillatory shear stress [12]. Like AVS, coronary atherosclerotic lesions more commonly occur at sites with the highest oscillatory shear stress, such as coronary vessel bifurcations [13].

Some published studies reported that WBV estimated by the de Simone formula was found to be associated with occurrence of MAC, and coronary collateral circulation in patients with chronic total occlusion, ST-elevation myocardial infarction, and coronary slow-flow phenomenon [14-17]. Moreover, increased Hct levels, as a component of WBV, inversely affect cerebral hemodynamics and result in an increased risk of neurological deficits $[8$, 18-20]. The strong relationship between high blood pressure and WBV and the components of WBV have also been shown in primary hypertension [21-23]. Coronary artery disease and AV disease may not generally coexist, and associations are complex. Even in the absence of the atherosclerotic process, altered blood flow patterns may be seen in patients with severe aortic stenosis [24-27]. The fluctuations in WBV are an indicator of wall shear stress, and enhanced WBV has been claimed to cause inflammation and vessel remodeling [28].

In a previous study, the rate of AVS was found to be higher in patients who had myocardial infarction without previous coronary risk factors, suggesting that undetectable atherosclerotic processes may have been higher in these patients than expected [1]. Therefore, traditional cardiovascular risk factors such as diabetes, hypertension, smoking, and hyperlipidemia are insufficient to explain the occurrence and development of AVS.

Higher WBV may be an indicator of AVS due to increased AV resistance. Although the WBV is the major component of the Virchow triad, related studies are limited because of the various materials needed for its evaluation. In this study, our findings have also demonstrated that WBV may be an important factor contributing to the development of AVS.

The limitations of this study include the fact that it is a case-control study with a relatively small number of patients; all the data were based on a single measurement, and direct measurements of blood viscosity with a viscometer were not done.

\section{Conclusions}

In this study, WBV at HSR and LSR were independently associated with AVS. Enhanced WBV could be an indicator of inflammation and vessel remodeling without evidence of outflow obstruction.

\section{Disclosure Statement}

The authors have no conflict of interest to report.

\section{References}

1 Otto CM, Lind BK, Kitzman DW, et al: Association of aortic-valve sclerosis with cardiovascular mortality and morbidity in the elderly. N Engl J Med 1999;341:142-147.

2 Yan AT, Koh M, Chan KK, et al: Association between cardiovascular risk factors and aortic stenosis: the CANHEART Aortic Stenosis Study. J Am Coll Cardiol 2017;69:1523-1532.

3 Xing Y, Warnock JN, He Z, et al: Cyclic pressure affects the biological properties of porcine aortic valve leaflets in a magnitude and frequency dependent manner. Ann Biomed Eng 2004;32:1461-1470.

4 Goldbarg SH, Elmariah S, Miller MA, et al: Insights into degenerative aortic valve disease. J Am Coll Cardiol 2007;50:1205-1213.
5 Cho YI, Cho DJ, Rosenson RS: Endothelial shear stress and blood viscosity in peripheral arterial disease. Curr Atheroscler Rep 2014; 16:1-10.

6 Baumgartner H, Hung J, Bermejo J, et al: Echocardiographic assessment of valve stenosis: EAE/ASE recommendations for clinical practice. J Am Soc Echocardiogr 2009;22:123; quiz 101-102.

7 Lang RM, Bierig M, Devereux RB, et al: Recommendations for chamber quantification: a report from the American Society of Echocardiography's Guidelines and Standards Committee and the Chamber Quantification Writing Group, developed in conjunction with the European Association of Echocardiography, a branch of the European Society of Cardiology. J Am Soc Echocardiogr 2005;18:14401463.
8 De Simone G, Devereux RB, Chien S, et al: Relation of blood viscosity to demographic and physiologic variables and to cardiovascular risk factors in apparently normal adults. Circulation 1990;81:107-117.

9 Barakat AI: A model for shear stress-induced deformation of a flow sensor on the surface of vascular endothelial cells. J Theor Biol 2001; 210:221-236.

10 Davies PF: Flow-mediated endothelial mechanotransduction. Physiol Rev 1995;75:519560 .

11 Balachandran K, Sucosky P, Yoganathan AP: Hemodynamics and mechanobiology of aortic valve inflammation and calcification. Int J Inflam 2011;2011:263870. 
12 Agmon Y, Khandheria BK, Meissner I, et al: Aortic valve sclerosis and aortic atherosclerosis: different manifestations of the same disease? Insights from a population-based study. J Am Coll Cardiol 2001;38:827-834.

13 Mohler ER 3rd: Mechanisms of aortic valve calcification. Am J Cardiol 2004;94:13961402.

14 Cetin MS, Ozcan Cetin EH, Balci KG, et al: The association between whole blood viscosity and coronary collateral circulation in patients with chronic total occlusion. Korean Circ J 2016;46:784-790.

15 Ozcan Cetin EH, Cetin MS, Canpolat U, et al: The forgotten variable of shear stress in mitral annular calcification: whole blood viscosity. Med Princ Pract 2015;24:444-450.

16 Cetin EH, Cetin MS, Canpolat U, et al: Prognostic significance of whole blood viscosity estimated by de Simone's formula in STelevation myocardial infarction. Biomark Med 2016;10:495-511.

17 Cetin MS, Ozcan Cetin EH, Canpolat U, et al An overlooked parameter in coronary slow flow phenomenon: whole blood viscosity. Biomark Med 2015;9:1311-1321.
18 Keatinge WR, Coleshaw SR, Easton JC, et al: Increased platelet and red cell counts, blood viscosity, and plasma cholesterol levels during heat stress, and mortality from coronary and cerebral thrombosis. Am J Med 1986;81:795800.

19 Most AS, Ruocco NA, Gewirtz H: Effect of a reduction in blood viscosity on maximal myocardial oxygen delivery distal to a moderate coronary stenosis. Circulation 1986;74: 1085-1092.

20 Tohgi $\mathrm{H}$, Yamanouchi $\mathrm{H}$, Murakami M, et al: Importance of the hematocrit as a risk factor in cerebral infarction. Stroke 1978;9:369-374.

21 Tarazi RC, Frohlich ED, Dustan HP, et al: Hypertension and high hematocrit: another clue to renal arterial disease. Am J Cardiol 1966; 18:855-858

22 Letcher RL, Chien S, Pickering TG, et al: Direct relationship between blood pressure and blood viscosity in normal and hypertensive subjects: role of fibrinogen and concentration. Am J Med 1981;70:1195-1202.

23 Cloix J-F, Devynck M, Brentano J, et al: Plasma protein changes in primary hypertension in humans and rats. Hypertension 1983;5: $128-134$
24 Kaufmann P, Vassalli G, Lupi-Wagner S, et al: Coronary artery dimensions in primary and secondary left ventricular hypertrophy. J Am Coll Cardiol 1996;28:745-750.

25 Marcus ML, Doty DB, Hiratzka LF, et al: Decreased coronary reserve: a mechanism for angina pectoris in patients with aortic stenosis and normal coronary arteries. N Engl Med 1982;307:1362-1366.

26 Nadell R, DePACE NL, Ren J-F, et al: Myocardial oxygen supply/demand ratio in aortic stenosis: hemodynamic and echocardiographic evaluation of patients with and without angina pectoris. J Am Coll Cardiol 1983;2:258262

27 Petropoulakis PN, Kyriakidis MK, Tentolouris CA, et al: Changes in phasic coronary blood flow velocity profile in relation to changes in hemodynamic parameters during stress in patients with aortic valve stenosis. Circulation 1995;92:1437-1447.

28 Silber HA, Bluemke DA, Ouyang P, et al: The relationship between vascular wall shear stress and flow-mediated dilation: endothelial function assessed by phase-contrast magnetic resonance angiography. J Am Coll Cardiol 2001;38:1859-1865. 